\title{
Preparing Internal Medicine Residents to Provide Primary Care for Women: Gender-Specific Clinics May Be the Answer
}

J Gen Intern Med 36(9):2859-60

DOI: $10.1007 / \mathrm{s} 11606-020-05985-\mathrm{x}$

(c) Society of General Internal Medicine 2020

\section{INTRODUCTION}

General internists must have skills to adequately screen for, recognize, evaluate, and treat gender-specific concerns for women patients. However, nearly $25 \%$ of internal medicine (IM) residency programs have no dedicated women's health (WH) opportunities, ${ }^{1}$ and prior studies have demonstrated inadequate levels of exposure to $\mathrm{WH}$ and low rates of selfrated competence in both IM trainees and practicing physicians. $^{2-4}$

Given this training gap, a needs assessment was undertaken to inform the development of a WH curriculum within our IM residency program. We hypothesized that despite regular didactic teaching and an optional WH elective, residents across all clinic sites would report low frequency, confidence, and adequacy of training in management of common $\mathrm{WH}$ issues.

\section{METHODS}

This study evaluated residents in our urban, academic IM residency program. Residents are assigned to a continuity clinic during their intern year, where they provide longitudinal care to a panel of patients throughout their training. All clinics are co-ed except the Veterans Affairs (VA) clinic, where residents divide time between an "all comers" General Internal Medicine Clinic and a dedicated Women's Clinic.

We surveyed residents at two didactic sessions in 20172018 about their perceived adequacy of training, confidence, and self-reported frequency in managing 12 common $\mathrm{WH}$ topics, as well as interest in additional training for common WH procedures. Adequacy of training and confidence were assessed with a 5-point Likert scale. WH topics were chosen based on competency recommendations for IM residents from

Prior Presentations Oral research abstract presentation at the Society of General Internal Medicine Northwest Regional Meeting, January 2018 (presented subset of this data)

Received May 7, 2020

Accepted June 12, 2020

Published online June 24, 2020 several professional societies. ${ }^{1}$ Our Institutional Review Board reviewed the study and found it exempt.

We calculated composite scores for adequacy of training, confidence, and frequency of management across topics. Multivariate regression models were used to examine the degree to which outcomes were predicted by gender, post-graduate year, and continuity clinic.

\section{RESULTS}

Eighty-nine of 95 residents (94\%) in attendance responded to the survey, corresponding to $58 \%$ of the total number of residents (168) in the program. Twenty-six percent of residents had continuity clinics at the VA, $28 \%$ at the universityaffiliated GIM clinic (UC), and 18\% at the clinic associated with the county hospital (CHC).

The average composite confidence score was 3.1 out of 5.0 (SD 0.7, range 2.6-3.8) (Table 1). Mean composite adequacy of training score was 3.0 out of 5.0 (SD 0.7, range 2.3-3.7). Nearly $1 / 3$ of respondents (30\%) reported never managing at least one of the $12 \mathrm{WH}$ topics over the last 6 months.

Residents with clinics at the VA had significantly higher overall confidence and adequacy scores compared with trainees at UC or CHC ( $p$ values $<0.01$ ) (Table 2). Trainees at the VA reported more frequent management of WH topics compared with those at UC or CHC ( $p$ values $<0.01)$. Respondents with clinics at $\mathrm{UC}$ and $\mathrm{CHC}$ were more likely to desire additional training in $\mathrm{WH}$ procedures compared with those at the VA, including obtaining pap smears for cervical screening $(\mathrm{OR}=10.1,95 \%$ CI $2.8-47.1$; and $\mathrm{OR}=19.4,95 \%$ CI 3.4-112.0) and wet mount preparation and interpretation (UC only) $(\mathrm{OR}=8.6,95 \%$ CI $2.0-37.8)$.

\section{DISCUSSION}

This study demonstrates marked variation in exposure to, perceived adequacy of training, and confidence in managing common WH issues across training sites within an IM residency. Results indicate that residents have low frequency of exposure to $\mathrm{WH}$ topics and desire more procedural training.

We anticipated that residents would report low frequency, confidence, and adequacy of training in management of WH issues, regardless of clinic site. Instead, we discovered that 
Table 1 Summary of Confidence and Perceived Adequacy of Training Scores by Topic or Exam Component

\begin{tabular}{|c|c|c|c|c|}
\hline & \multicolumn{2}{|c|}{ Confidence* } & \multicolumn{2}{|c|}{ Adequacy of training ${ }^{\dagger}$} \\
\hline & Average & SD & Average & SD \\
\hline Menstrual disorders & 2.8 & 0.8 & 2.6 & 0.7 \\
\hline New breast lump & 3.1 & 0.9 & 2.9 & 0.9 \\
\hline Contraception & 3.5 & 1.1 & 3.4 & 1.0 \\
\hline Menopause & 2.7 & 1.0 & 2.4 & 0.8 \\
\hline Osteoporosis & 3.1 & 0.8 & 3.1 & 0.8 \\
\hline Screening for cervical cancer & 3.6 & 0.9 & 3.5 & 0.9 \\
\hline Preconception counseling & 2.7 & 1.3 & 2.7 & 1.2 \\
\hline Intimate partner violence & 2.7 & 1.2 & 2.4 & 1.1 \\
\hline Breast exam & 3.2 & 1.0 & 3.1 & 1.0 \\
\hline Pelvic exam & 3.5 & 0.9 & 3.5 & 0.9 \\
\hline Obtaining pap smear & 3.7 & 1.0 & 3.6 & 0.9 \\
\hline Wet mount prep and interpretation & 2.7 & 1.2 & 2.8 & 1.1 \\
\hline
\end{tabular}

$* 1=$ no confidence at all, $5=$ complete confidence

$\dagger 1=$ not at all adequate, $5=$ completely adequate

Table 2 Multivariate Regression Models for Composite Confidence, Adequacy of Training, and Frequency of Management Scores

\begin{tabular}{|c|c|c|c|c|c|c|c|c|c|}
\hline \multirow[b]{2}{*}{ Variables } & \multicolumn{3}{|c|}{ Confidence } & \multicolumn{3}{|c|}{ Adequacy of training } & \multicolumn{3}{|c|}{ Frequency of management } \\
\hline & $B^{*}$ & $p$ & $95 \% \mathrm{CI}$ & $B^{*}$ & $p$ & $95 \% \mathrm{CI}$ & $B^{*}$ & $p$ & $95 \% \mathrm{CI}$ \\
\hline Female gender & 0.30 & $0.032 * *$ & $0.03,0.57$ & 0.31 & $0.040 * *$ & $0.01,0.60$ & 0.23 & $0.001 * *$ & $0.10,0.37$ \\
\hline $\begin{array}{l}\text { PGY } \\
\text { Clinic site } \\
\text { VA (reference) }\end{array}$ & 0.26 & $0.004 * *$ & $0.09,0.43$ & 0.18 & 0.065 & $-0.01,0.37$ & 0.01 & 0.062 & $-0.00,0.17$ \\
\hline $\begin{array}{l}\mathrm{UC} \\
\mathrm{CHC}\end{array}$ & $\begin{array}{l}-0.48 \\
-0.61\end{array}$ & $\begin{array}{l}0.007 * * \\
0.002 * *\end{array}$ & $\begin{array}{l}-0.83,-0.13 \\
-0.99,-0.23\end{array}$ & $\begin{array}{l}-0.55 \\
-0.68\end{array}$ & $\begin{array}{l}0.005 * * \\
0.002 * *\end{array}$ & $\begin{array}{l}-0.93,-0.17 \\
-1.09,-0.26\end{array}$ & $\begin{array}{l}-0.23 \\
-0.40\end{array}$ & $\begin{array}{l}0.002 * * \\
0.000 * *\end{array}$ & $\begin{array}{l}-0.45,-0.11 \\
-0.34,-0.01\end{array}$ \\
\hline
\end{tabular}

$* B=$ standardized coefficients

$* * p<0.05$

residents with continuity in a dedicated women's clinic in addition to a "regular" primary care clinic (VA-based residents), had significantly more exposure to, confidence in managing, and higher rates of perceived adequacy of training compared with residents working at sites without dedicated women's clinics (UC- and CHC-based residents).

These data suggest that longitudinal experiences in women's clinics may provide richer learning than combined co-ed clinics, didactics, or shorter clinical electives, a finding supported by prior studies. ${ }^{5,6}$ As such, an optional longitudinal curriculum and clinical experience in WH was built into our program.

Training a workforce that is prepared to address the needs of all patients is a fundamental task of graduate medical education. Until programs are able to close knowledge gaps for trainees, women remain at risk of poorer quality, more fragmented care.

Acknowledgments: Contributors: Michelle Garrison, $\mathrm{PhD} M P H$

Meagan S. Williams, $M^{1}$

Adelaide H. McClintock, $M^{1}$

${ }^{1}$ Division of General Internal Medicine, Department of Medicine, University of Washington,

Seattle, WA, USA
Corresponding Author: Meagan S. Williams, MD; Division of General Internal Medicine, Department of Medicine, University of Washington Seattle, WA, USA (e-mail: meagsw@uw.edu).

\section{Compliance with Ethical Standards:}

Conflict of Interest: The authors have no conflicts of interest.

\section{REFERENCES}

1. Casas RS, Hallett LD, Rich CA, Gerber MR, Battaglia TA. Program Directors' Perceptions of Resident Education in Women's Health: A National Survey. J Womens Health (Larchmt). 2017;26(2):133-140.

2. Hsieh E, Nunez-Smith M, Henrich JB. Needs and priorities in women's health training: perspectives from an internal medicine residency program. J Womens Health (Larchmt). 2013;22(8):667-672.

3. Dixon JG, Bognar BA, Keyserling TC, et al. Teaching women's health skills: confidence, attitudes and practice patterns of academic generalist physician. J Gen Intern Med. 2003;18(6):411-418.

4. Wayne DB, DaRosa DA. Evaluating and enhancing a women's health curriculum in an internal medicine residency program. J Gen Intern Med. 2004; 19(7):754-759.

5. Swedish KA. Introducing a Women's Health Clinic Improves Resident Comfort and Competence in Performing Women's Health Exams. J Gen Intern Med. 2019;34(7): 1081-1082.

6. Spencer AL, Bost JE, McNeil M. Do Women's health internal medicine residency tracks make a difference? J Womens Health (Larchmt). 2007;16(8):1219-1223.

Publisher's Note: Springer Nature remains neutral with regard to jurisdictional claims in published maps and institutional affiliations. 